International Journal of Advanced Biological and Biomedical Research Available online at http:www.ijabbr.com

Volume 8, Issue 2 (2020) pp. 214-224

DOI:10.33945/SAMI/IJABBR.2020.2.10

Original Article

\title{
PI3K/ Akt/ mTOR and CDK4 Combined Inhibition Enhanced Apoptosis of Thyroid Cancer Cell Lines
}

\section{Neda Hamidipour¹, Mehdi Fazeli*,1, Mehdi Hedayati², Mohsen Dehghani' ${ }^{3}$,Razieh Gerami ${ }^{1,2}$}

${ }^{1}$ Department of Basic Sciences, School of Veterinary Medicine, Shiraz University, Shiraz, Iran ${ }^{2}$ Cellular and Molecular Endocrine Research Center, Research Institute for Endocrine

Sciences, ShahidBeheshti University of Medical Sciences, Tehran, Iran

${ }^{3}$ RayanPars pharmaceutical company, Fars, Shiraz, Iran

*Corresponding Author E-mail:mfazeli@shirazu.ac.ir

Received: 26 June 2019, Revised:13 November2019, Accepted: 18 November 2019

\begin{abstract}
Introduction: Thyroid cancer is a malignant disease which could hardly be prognosticated. The PI3K/Akt/mTOR and Cyclin-DependentKinase 4 (CDK4) pathways are vital regulators of tumor cell proliferation and survival. The present study was accordingly designed to use dual inhibition of such pathways to kill thyroid cancer cells.

Methods and materials: The effects of each inhibitors on human ATC and BCPAP cell lines wereevaluated by MTT assay. The right concentrations of inhibitors were determined and synergistic effects of such inhibitors were evaluated by bax/bcl-2 mRNA ratio, Caspase3,and Caspase- 9 activity assay as well as Akt, mTOR,and CDK4.

Results:Our finding showed thatboth ATC and BCPAP cell proliferation is significantly inhibited by PD-332991(PD) and NVP-BEZ235 (NVP) in a time and concentrationdependent manner $(\mathrm{P}<0.05)$, however, the BCPAP cells were more sensitive than ATC cells. Our data also revealed that NVP treatment significantly decreasedthe phosphorylation state of both AKT and mTOR. Nonetheless, PD treatment alone increased activation of both AKT and mTORwhereascombination treatment of NVP and PD1 significantly decreased AKT and mTOR phosphorylation $(\mathrm{P}<0.001)$. NVP and PD treatment either alone or in a combination also decreased Retinoblastoma phosphorylation. Combination of NVP and PD similarly decreased Cyclin D1 expression.In addition, our data of Caspase 8 and Caspase 3 as well as Bax/Bcl-2 ratio indicated that the combinationof NVP and PD induced cell apoptosis significantly $(\mathrm{P}<0.05)$.
\end{abstract}

Conclusion: The present study suggests thatinhibition ofPI3K and CDK4 is the effective treatment for bothresistant and sensitivethyroid cancer cell line.

Key words: Thyroid cancer,Carcinoma,Apoptosis, NVP-BEZ235, PD-332991 


\section{Introduction}

Thyroid cancer arising from follicular and parafollicular cells is one of the most rapidly growing endocrinecancers all over the world(Nix et al., 2005;Zarkesh et al., 2018). It has been predicted that the incidence rate of thyroid cancer will rise by the year 2030 to make it the fourth leading cancer prevalence (Rahib et al., 2014).Histological study of this cancer indicated that it can be classified into four majortypes, including papillary carcinoma follicular carcinoma, medullary carcinoma and undifferentiated carcinoma(Hedinger et al., 1989). Despite numerous therapeutic advances, itseems to be anincurable cancer.To date, surgery followed by the administration of systemic chemotherapy agents remains an effective treatment for the advanced stage of thyroid cancer(Mazzaferri andKloos, 2001). Unfortunately,not only isthe initial response to chemotherapy is satisfactory,but the tumors become resistant to chemotropic agents(Wartofsky and Van Nostrand, 2016). Nevertheless, advances in molecular biology have provided a possibility to develop a novel effective therapeutic strategy for thyroid cancer.

Phosphoinositide 3-kinase (PI3K) is a class of kinases that play a key role in the cell growth regulation, proliferation, and differentiation. Based on sequence homology and substrate specificity, the kinase family of enzyme is divided into three classes as follows: class I, which is activated downstream of cell surface receptors, Class IA consisting of the catalytic subunits $\mathrm{p} 110 \alpha, \mathrm{p} 110 \beta$, and $\mathrm{p} 110 \delta$ and class IB,which operates downstream of GPCRs(Brown and Toker, 2015).A large body of experiments have shownthat the PI3K pathway is greatly activated in thyroid tumors by several different mechanisms including somatic activating mutation, amplification of genes encoding key components, and upstream receptor tyrosine kinase overexpression(Nozhat et al., 2018). The targeting PI3K pathway using pharmacological small molecule inhibitors has become a potential therapeutic strategy(Wu et al., 2015).NVPBEZ235 (NVP) is a small molecule PI3K inhibitor which inhibits ATM and Rad3-related (ATR)as well. Emerging evidencehas indicated that glioblastoma treatment islikely to be significantly improvedthroughthe combination of ionizing radiation(del Alcazar et al., 2014).Unlike other specificPI3Kinhibitors, this is currently used in phase I/II clinical trials as an mTOR inhibitor in animal study(Peyton et al., 2011). Cyclin-dependent kinases (CDKs) are a family of protein kinases characterized by needing to a separate subunit called Cyclin, whichplaysa vital role inthe cell cycle. CDKs are divided into three cell-cycle-related subclasses (Cdk1, Cdk4, and Cdk5) and five transcriptional subfamilies (Cdk7, Cdk8, Cdk9, Cdk11,and Cdk20). A growing number of studies in the present field provide evidence to support the hypothesis that deregulation of these proteins can lead to several malignancies. For instance, Pojo and associates have shown that CDK4 is up-regulated in ATC tumor cells.Further, they have indicated that CDK4 inhibitors such as Palbociclib(PD-0332991) act as an effective reagents to ATC treatment(Pojo et al., 2017).

Emerging data contributed to identifying a strategy to approach anti-proliferative ability against tumor cells. For instance, combined inhibition of PI3K and mammalian target of rapamycin complex (mTORC) may enhance the clinical activity to reduce tumor cell resistance (Elkabets et al., 2013). Moreover, co-treatment ofPI3K and mTOR inhibitorshave made their way into clinical trials(Markman et al., 2012).

Our present study was designed to identify additional strategies that may increase the efficacy of treatment against thyroid cancer cell lines proliferation. The current study also tried to investigate the molecular mechanism underlying synergistic activity of PI3K and CDK4 
inhibitors by the evaluation of downstream pathways to support the hypothesis for the treatment of thyroid cancer.

\section{Experimental}

\section{Cells and materials}

Human ATC and BCPAP as the resistant and sensitive thyroid cancercells wereprovided from Pasteur Institute of Iran (Tehran, Iran). The Dulbecco's modified Eagle medium (DMEM), fetal bovine serum (FBS) and trypsin were provided from Gibco (Life technology, USA), while phosphate buffered saline (PBS), the 3-[4, 5-dimethylthiazol-2-yl]-2, 5 diphenyltetrazolium bromide (MTT), protease inhibitor cocktail, penicillin-streptomycin, and ethidium bromide, NVP and PDwere purchased from Sigma Aldrich(MO, USA). Caspase activity assay kits and antibodies were alsoobtained from (Cell Signaling Technology, Inc., Danvers, MA, USA). The anti-Akt, pAKT, mTor, CDK4 and GAPDH respective secondary antibodies were purchased from Santa Crus (CA, USA). The chemiluminescent detection system was purchased from TaKaRa (Tokyo, Japan) and other chemicals used in this study were obtained from Merck (Darmstadt, Germany).

\section{Cell culture}

The BCPAP and ATC cells as a sensitive and resistant thyroid cancer cells were used for this study. Following previous research (Gheysarzadeh and Yazdanparast, 2012), BCPAP were cultured in RPMI 1640 (w L-glutamate) completed by fetal bovine serum (10\%), penicillin/streptomycin (2\%) and amphotericine B (1\%),and in line with our previous study (Nozhat et al., 2018), the ATC cells were cultured in Dulbecco's Modified Eagle Medium, completed by fetal bovine serum (10\%), penicillin/streptomycin (2\%), amphotericine B (1\%).

\section{Cell viability assay}

The cells $\left(5 \times 10^{4}\right.$ cells per well) were cultured into a 96-well plate and incubated in a $\mathrm{CO}_{2}$ incubator at $37{ }^{\circ} \mathrm{C}$ for $24 \mathrm{~h}$ as described previously (Gheysarzadeh and Yazdanparast, 2012). The indicated concentrations of NVP and PD were added to each well and then after indicating the time, $10 \mu \mathrm{l} \mathrm{MTT} \mathrm{(5} \mathrm{mg/ml)} \mathrm{was} \mathrm{added} \mathrm{to} \mathrm{each} \mathrm{sample} \mathrm{and} \mathrm{incubated} \mathrm{again} \mathrm{for} 4 \mathrm{~h}$ at $37^{\circ} \mathrm{C}$ in dark. Finally, the production of Formazan by the viable cells was measured at $570 \mathrm{~nm}$ using a multiwell plate reader (BioTek, Winooski, VT, USA).

\section{Caspase- 3 and 9 activity assay}

The treated and untreated cells $\left(5 \times 10^{5}\right)$ were homogenized on ice followed by lysing with cell lysis buffer and incubated on ice for $1 \mathrm{~h}$. The homogenates were then centrifuged at $14,000 \mathrm{~g}$ for $15 \mathrm{~min}$ at $4^{\circ} \mathrm{C}$. The pellets were discarded andobtained supernatant was then subjected to Caspase- 3 and 9 activity evaluation according to the manufacturer's instruction (Cell Signaling Technology, Inc., Danvers, MA, USA). Protein content was assessed by the BCA protein assay method (Hamzeloo-Moghadam et al., 2015). Results of at least three independent experiments were first normalized based on protein content using the BCA protein assay method and their values were expressed as fold change in compared with the untreated cells. 


\section{Analysis of gene expression by real-time quantitative PCR}

The cells were cultured in 6-well plates in a density of $5 \times 10^{5}$ and after $24 \mathrm{~h}$ they were treated with indicated concentration of NVP and/or PD in the complete growth medium. Total RNA was then extracted from cells using TRIsol according to the manufacturer's instruction. Total RNA was then reverse transcribed to cDNA using TaKaRatranscription kit, followed by Quantitative real-time RT-PCR analysis as described previously (Ahmed, 2005). In brief, the reaction mixture $(10 \mu \mathrm{l})$ containing $2 \mu \mathrm{l}$ of cDNA template, $1.5 \mu \mathrm{l}$ each of forward and reverse primers and SYBR Green RT-PCR master mix amplified based on SYBR Green method. Each cycle of amplification was as follows: denaturation at $95^{\circ} \mathrm{C}$ for $10 \mathrm{~min}$ and 35 cycles at $95^{\circ} \mathrm{C}$ for $30 \mathrm{~s}$, and $60^{\circ} \mathrm{C}$ for $20 \mathrm{~s}$. Primers used in the present study were as follows:bcl-2 forward, 5' CGA CTT CGC CGA GAT GTC CAG CCA G3'; bcl-2 reverse 5'ACT TGT GGC CCA GAT AGG CAC CCA G3'; bax forward, 5'AGG GTT TCA TCC AGG ATC GAG CAG3'; bax reverse, 5'ATC TTC TTC CAG ATG GTG AGC GAG3'; GAPDH forward, CAG CCT CAA GAT CAT CAG C; GAPDH reverse, GGC AGT GAT GGC ATG GAC T(Malekiet al., 2019). The melting curve was generated at the end of each examination. The gene expression was relatively quantified by $2^{-\triangle \Delta \mathrm{CT}}$ method and finally values were reported as mean $\pm \mathrm{SD}$ (Gheysarzadeh et al., 2018).

\section{Western blotting}

The cells were lysed using buffer containing 20mM TrisHCl (Ph7.5), 0.5\% NonidetP-40, 0.5mM PMSF, $100 \mathrm{mM}$ b-glycerol 3-phosphate, and $0.5 \%$ protease inhibitor cocktailfollowed by centrifugation at $14000 \mathrm{~g}$ for 10 minutes. The resulting supernatant was collected, aliquoted and stored in $-70{ }^{\circ} \mathrm{C}$ for western blotting analysis as indicated previously(Gheysarzadehet al., 2019; Gheysarzadeh et al., 2019). An equal concentration of each samplewas boiled for $10 \mathrm{~min}$ and loaded into a 10\% SDS-PAGE gel followed by transferring into a PVDF membrane. Nonspecific sites of the membrane were blocked with $3 \%$ bovine serum albumin in Tris-buffered saline for $2 \mathrm{~h}$ at room temperature and incubated with indicated primary antibodies. The samples were exposed to the secondary antibodies for $2 \mathrm{~h}$ and then the bound secondary antibodies were evaluated with the ECL western blotting detection system. The membrane was exposed to the X-ray film and all blots were normalized with GAPDH as a loading control using Image J software (National Institutes of Health, Bethesda, MD, USA).

\section{Statistical analysis}

Statistical analyses were performed using version 19 of SPSS software (Chicago, IL, USA). All examinations were set up in triplicates and the results were presented as the mean \pm standard deviation (SD). The Caspase activity assay and cell viability values obtained per each treatment were converted to the percentage of control cells. The effect of each treatment sample was compared with treated and untreated cells by student t-test andOne-Way ANOVA. The $\mathrm{P}<0.05$ was considered as statistically significant.

\section{Results and discussion}

\section{Synergistic inhibition of cell growth by a combination of NVP and PD}

In order to determine the effect of NVP and PD on cell viability, the exponentially growing Thyroid cancer cells were exposed to different concentrations of NVP and PD. Our results showed that the ATC cell proliferation is inhibited by $0-38 \%$ after $24 \mathrm{~h}$ exposure to $0.025-10$ 
$\mu \mathrm{M}$ of PD, $0-52 \%$ for $48 \mathrm{~h}$ and $1-60 \%$ for $72 \mathrm{~h}$ and $2-69 \%$ for $96 \mathrm{~h}$. Our data also indicated that the ATC cell proliferation is inhibited by $0-28 \%$ after $24 \mathrm{~h}$ exposure to $1-400 \mu \mathrm{M}$ of NVP, 0 $51 \%$ for $48 \mathrm{~h}$ and $1-56 \%$ for $72 \mathrm{~h}$ and $3-68 \%$ for $96 \mathrm{~h}$. Thesimilar pattern of cell viability was seen for BCPAP cells. However, the BCPAP cells were more sensitive than ATC cells. For instance,24 h incubation of BCAP cells to $5-2000 \mathrm{~nm}$ of PD leads to cell viability inhibition to 1$57 \%$ (Figure 1). In order to further analyze in a combination of these two compounds, the IC20 were used as indicatedby a previous study (Ashton, 2015).

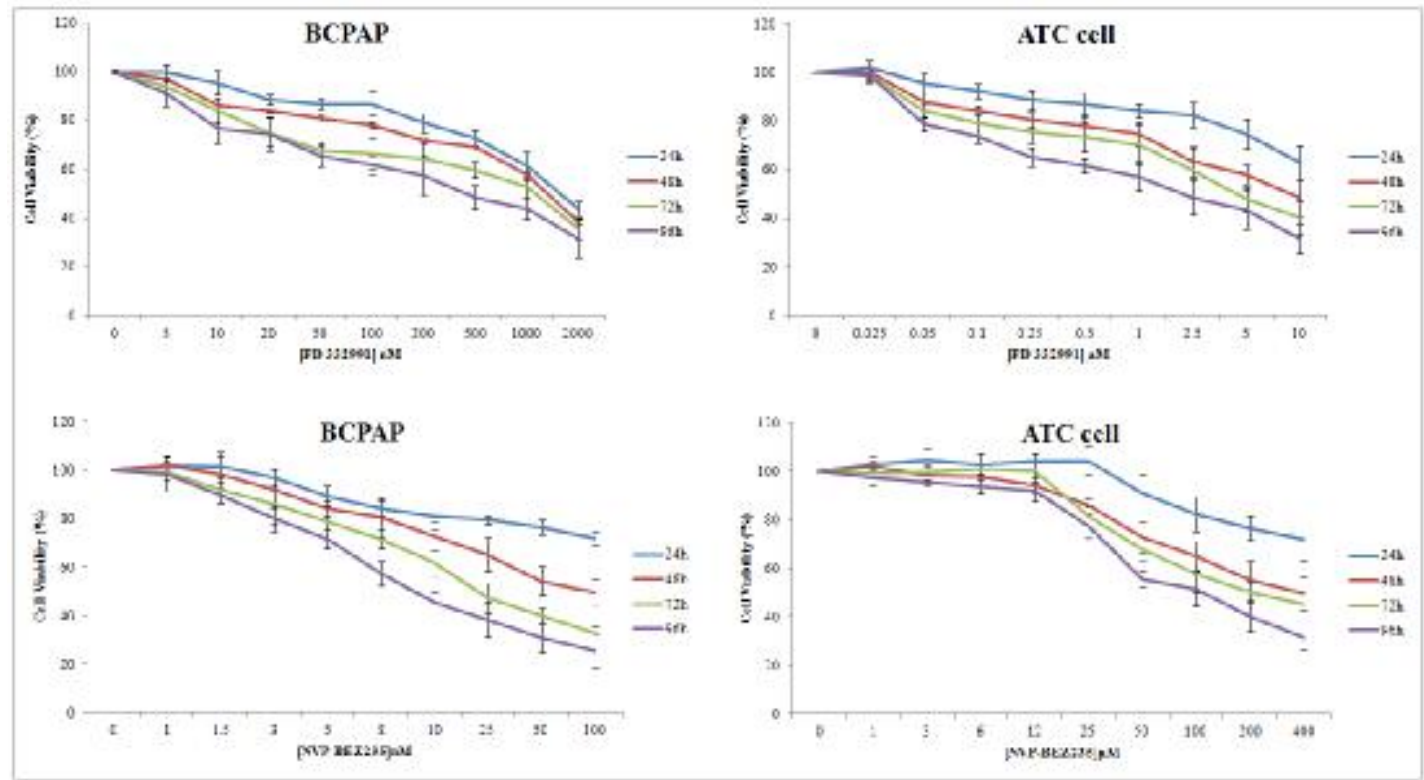

Figure1.Growth inhibitory effects of NVP-BEZ235 of PD-332991 on human ATC cell line

The cells were cultured in 96-well plates and treated with the indicated concentrations of NVP-BEZ235 of PD-332991. Following 12, 24 and $36 \mathrm{~h}$ of incubation, cell viability was determined using an MTT assay. The data presented as the means \pm SD of three independent experiments. Statistical significance: ${ }^{*} \mathrm{P}<0.05$, ${ }^{* *} \mathrm{P}<0.01,{ }^{* * *} \mathrm{P}<0.001$, t-test.

\section{Effects of NVP and PD on signaling pathways}

To gain a molecular understanding on NVP and PD synergistic effects, we examined the effects of these two inhibitors and their combination on the expression and/or phosphorylation status (after 24h) of a number of relevant elements of the proliferation signaling pathway. PI3K/AKT pathway, as one of the most important signaling pathway, is generally accepted to mediate tumor cell growth and cell survival. The Akt and mTOR are also the key downstream elements of this pathway (Pópuloet al., 2012). According to Figure 2, NVP treatment, regardless of PD,catastrophically led to a decrease in the extent of phosphorylated both AKT and mTOR whereas no considerable alteration was observed in the expression of total AKT and mTOR (after 24h). Whereas PD treatment alone increased activation of both AKT and mTOR, combination treatment of NVP and PD significantly decreased AKT and mTOR phosphorylation $(\mathrm{P}<0.001)$. NVP and PD treatment either alone or in a combination also decreased Retinoblastoma phosphorylation $(\mathrm{P}<0.05)$. NVP in a combination of PD alsodecreased Cyclin D1 expression $(\mathrm{P}<0.05)$. 


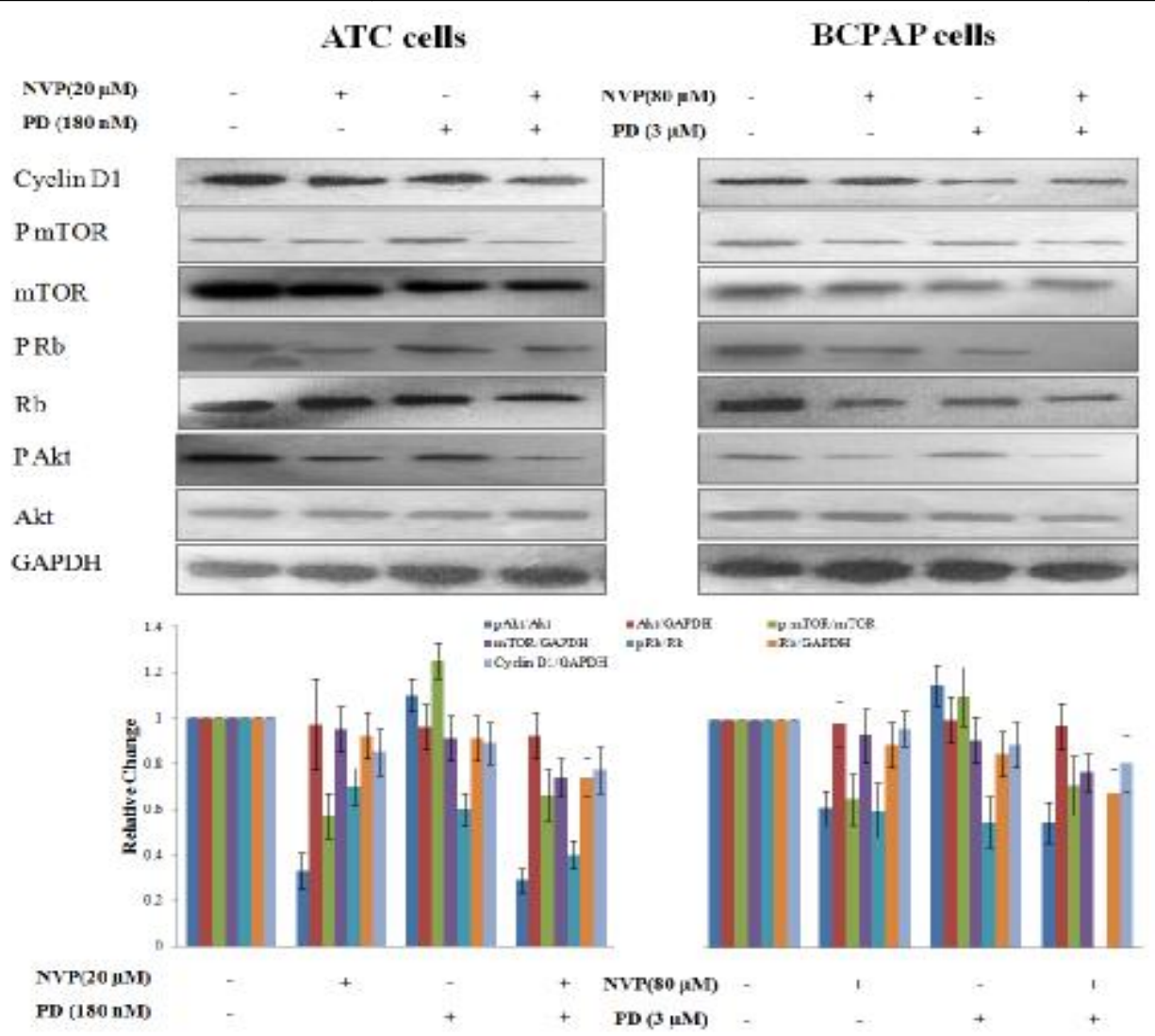

Figure 2.Effect of NVP-BEZ235 and PD-332991 on the CDK4 and downstream signaling elements of PI3K ATC cells

Cells were treated with indicated concentration of NVP-BEZ235 of PD-332991 either alone or in combination with each other for $24 \mathrm{~h}(\mathrm{~A})$. Western blotting bound were quantified based on un-phosphorylated protein (for Akt, mTOR, and RB) and GAPDH for other proteins. The data reported as the means \pm SD of three independent experiments.

\section{Effects of NVP and PD on apoptosis}

To further investigate the combination effectsofNVP and PDon apoptosis induction, the Bax/Bcl-2 ratio and Caspase activity assay were performed for ATC cells in response toNVP and PD either alone or in combination. The results indicated thatNVP and PD incubation of cells for 24 hsignificantly increased the Caspase- 8 and Caspase- 3 activity $(P<0.05)$. However, the combination of such compounds catastrophically increased both Caspase-8 and Caspase- 3 activity $(\mathrm{P}<0.001)$, and this increase was significantly more than each compound alone $(\mathrm{P}<0.05)$. Similarly, BCAP cells were exposed to NVP and PD in a lower concentration. Likewise, the results showed that NVP and PDexposure of cells for $24 \mathrm{~h}$ increased the Caspase- 8 and Caspase- 3 activity in a significant manner $(\mathrm{P}<0.05)$ while the combination of such inhibitors increased both Caspase- 8 and Caspase- 3 activity $(\mathrm{P}<0.001)$, and thatthe Caspase activities for the combination of these compounds were significantly higher than each compound alone $(\mathrm{P}<0.05)$. 
In addition, the Bax/Bcl-2 ratio also further confirmed the combination effects ofNVP and PD on apoptosis induction. As illustrated in Figure 3B, NVP and PD incubation of ATC cells for $24 \mathrm{~h}$ significantly increased the Bax and reduced Bcl-2 mRNA $(\mathrm{P}<0.05)$. The combination of such compounds synergistically increased Bax and decreased Bcl-2 $(\mathrm{P}<0.001)$. However, therise of Bax/Bcl-2 ratio for a combination of NVP and PD was significantly more than each compound alone $(\mathrm{P}<0.05)$. BCPAP cells exhibiteda similar patternas well.

Further, our finding showed that the Bax/Bcl-2 ratioincreased significantly in the presence ofNVP and PD for $24 \mathrm{~h}(\mathrm{P}<0.05)$. The combination of such agents increasedBax/Bcl-2 ratio synergistically $(\mathrm{P}<0.001)$. However, the $\mathrm{Bax} / \mathrm{Bcl}-2$ ratio for the combination of these compounds was significantly higher than that ofeach compound alone $(\mathrm{P}<0.05)$.

A

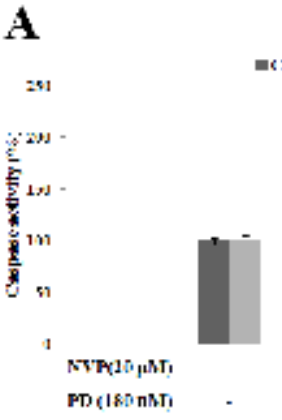

B.

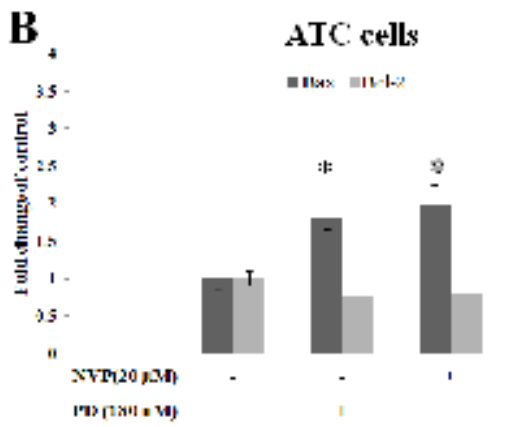

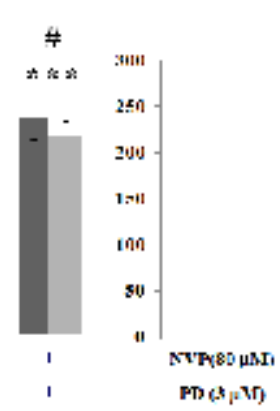

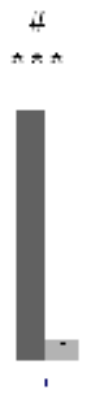

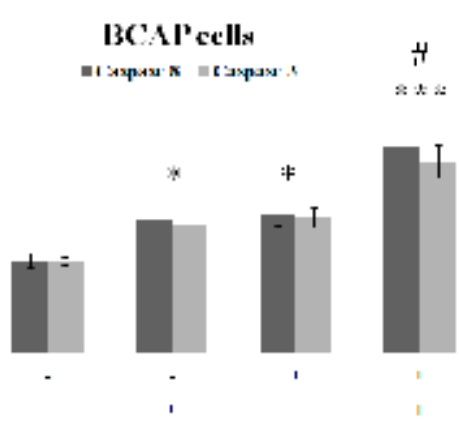

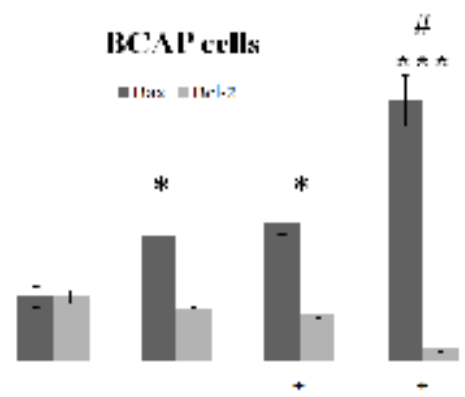

Figure 3.Effect of NVP-BEZ235 and PD-332991 alone and in combination with together, on apoptosis of ATC cells

The cells were treated with indicated concentration of NVP-BEZ235 of PD-332991 either alone or in combination with each other for $24 \mathrm{~h}$ and then the Caspase activity (A) and $\mathrm{Bax} / \mathrm{Bcl}-2$ ratio were also evaluated (B). The presented values were reported as the means $\pm \mathrm{SD}$ of three independent experiments. Statistical significance: ${ }^{*} \mathrm{P}<0.05,{ }^{* *} \mathrm{P}<0.01$, ${ }^{* * *} \mathrm{P}<0.001$, t-test.

\section{Discussion}

Despite a decade of unremitting studies and clinical trials, such as surgical removal of tumor and chemotherapy,thyroid cancer treatment has not significantly improved. Such unfavorable outcomes are due in part to the invasive nature of tumor cell and their resistance to treatment(Tagliaferri et al., 2018). In addition, most of the alterations involved in thyroid 
cancer are due to large inactivation or down-regulation of tumor suppressor genes, and upregulation or activation of oncogenic signaling cascades. These signaling alterations make the development of effective therapies very difficult(Brown et al., 2011).Anaplastic thyroid cancer (ATC) cells which have been thought to develop from papillary thyroid cancer is an extremely aggressive type of thyroid cancer with high mortality rate,exhibiting resistance to any chemotherapy or radiotherapy. Another papillary thyroid cancer cell in this study was BCPAP which was more sensitive to inhibitors(Lopes-Ventura et al., 2018).

The most frequent altered gene in thyroid cancers is PI3K signaling cascade(Vasko et al., 2004). This pathway seems to be activated by insulin and IGF-1 to induce cell growth (Ansari et al., 2017; Jafari et al., 2018).Still another signaling cascade such as epidermal growth factor is also involved in thyroid cancer (Maleki et al., 2018). The upstream element of this cascade is a complex of proteins present in cytoplasmcatalyzing the phosphorylation of D3 position of phosphatidylinositol.Akt is a protein located in a downstream of PI3K. Phosphorylated Akt (pAkt) is the activated form of Akt, which is able to enter cellular nuclei to phosphorylate a series of substrates and performs its biological functions(Hou et al., 2007). PI3K/Akt pathway is generally believed to act as a very important signaling pathway of cancer progression, which is closely related to cell proliferation, metabolism, and tumor growth. It also appears to activate other signaling pathways including Wnt- $\beta$-catenin, HIF1 $\alpha$, FOXO3, and NF- $\mathrm{BB}$ pathways. The activated form of PI3Kisalso capable ofphosphorylating a series of downstream target proteins such as Bad, Caspase 9, p2l, and mTOR which generally promote cell survival(Vivanco and Sawyers, 2002).

The most frequent altered signaling cascades in thyroid cancer arePI3K/Akt/mTOR and CDK4 which are responsible for the proliferation and cell cycle regulation, respectively.Other proliferative signaling pathwaysare Cyclin D1 and CDK4 which have been known to increase in aggressive thyroid cancer (Lee et al., 2018).It has thereforebeen suggested that dual inhibition of these pathways extremely inhibit cell growth.

Our results indicated that the CDK4/6 inhibitor reduced cell viability of both ATC and BCPAP cells of thyroid cancers (Figure 1). The similar pattern of growth inhibition was also shown for $\mathrm{PI} 3 \mathrm{~K} / \mathrm{Akt} / \mathrm{mTOR}$ inhibition conducting researcher to use in combination together. The effect of such inhibitors on signaling elements also indicated that PI3K inhibition led to a significant reduction on Aktand mTOR phosphorylation (Figure 2).As previously presented, CDK-4 inhibitor exerted its cytostatic effect by promotingthe G0-G1 phase cell cyclearrest. Here we additionally presented that CDK-4 inhibitionled toa slight reduction ofRbphosphorylation.

On the other hand, apoptosis is often accompanied by either PI3K or CDK4 inhibition. Our data also indicated that, as presented in Figure 3, theinhibition of such pathways is associated with apoptosis induction.A molecular mechanism by which Akt, mTOR,andRB can exert a proapoptotic function in a wide variety of cancer has been recently proposed. For instance, $\mathrm{Rb}$ has been shown to exert tumor suppression primarily through direct binding and suppression of the E2F transcription factor.In addition, PI3Kinase inhibition resulted in inactivation of Akt,leading to a reduction of cell survival and promoting apoptosis.PI3Kinase inhibition also eventually inactivates mTOR which is complicated to cell growth inhibition.

In conclusion, regardless of several limitations this study facedsuch as knocking down of genes of interest and apoptosis determination methods,itrevealed that either inhibition of PI3K/Akt/mTOR or CDK4 reduces cell proliferation by inducing apoptosis. However, the combinations of these inhibitors reduce cell proliferation more effectivelyand induce apoptosis.

\section{Acknowledgements}


The authors appreciates research council of Shiraz University for its financial supports.

\section{References}

Ahmed, H. (2005). Principles and reactions of protein extraction, purification, and characterization: CRC press New York.

Ansari, A, Gheysarzadeh, A, Mofid, MR. (2017).The interaction of insulin-like growth factor binding protein 3 (IGFBP-3) in insulin-like growth factor (IGF)-independent system.J. Isfahan Med. School, 35(451):1452-1461.

Ashton, JC. (2015). Drug Combination Studies and Their Synergy Quantification Using the Chou-Talalay Method.Cancer Res., 75(11):400-446.

Brown, RL, de Souza, JA, Cohen, EE. (2011). Thyroid cancer: burden of illness and management of disease. J. Cancer, 2:193-199.

Brown, KK, Toker, A. (2015). The phosphoinositide 3-kinase pathway and therapy resistance in cancer.F1000prime Rep., 7:13-21.

del Alcazar, CRG, Hardebeck, MC, Mukherjee, B, Tomimatsu, N, Gao, X, Yan, J, Xie, XJ, Bachoo, R, Li, L, Habib, AA, Burma, S. (2014). Inhibition of DNA double-strand break repair by the dual PI3K/mTOR inhibitor NVP-BEZ235 as a strategy for radiosensitization of glioblastoma. Clin. Cancer Res., 20(5):1235-1248.

Elkabets, M, Vora, S, Juric, D, Morse, N, Mino-Kenudson, M, Muranen, T, Tao, J, Campos, AB, Rodon, J, Ibrahim, YH, Serra, V, Rodrik-Outmezguine, V, Hazra, S, Singh, S, Kim, P, Quadt, C, Liu, M, Huang, A, Rosen, N, Engelman, JA, Scaltriti, M, Baselga, J. (2013). mTORC1 inhibition is required for sensitivity to PI3K p110 $\alpha$ inhibitors in PIK3CA-mutant breast cancer. Sci. Translat. Med., 5(196):1-28.

Gheysarzadeh, A, Yazdanparast, R. (2012).Inhibition of H2O2-induced cell death through F0X01 modulation by EUK-172 in SK-N-MC cells.Eur.J. Pharmacol., 697(1):47-52.

Gheysarzadeh, A, Ansari, A, Emami, MH, Razavi, AE, Mofid, MR. (2019). Over-expression of lowdensity lipoprotein receptor-related Protein-1 is associated with poor prognosis and invasion in pancreatic ductal adenocarcinoma. Pancreatology, 19:429-435.

Gheysarzadeh, A, Bakhtiari, H, Ansari, A, EmamiRazavi, A, Emami, MH, Mofid, MR. (2019).The insulin-like growth factor binding protein-3 and its death receptor in pancreatic ductal adenocarcinoma poor prognosis. J. Cell. Physiol., 234:23537-23546.

Gheysarzadeh, A, Sadeghifard, N, Afraidooni, L, Pooyan, F, Mofid, MR, Valadbeigi, H, Bakhtiari, H, Keikhavani, S. (2018). Serum-based microRNA biomarkers for major depression: MiR-16, miR135a, and miR-1202. J. Res. Med. Sci., 23:69-81.

Hamzeloo-Moghadam, M, Aghaei, M, Fallahian, F, Jafari, SM, Dolati, M, Abdolmohammadi, MH, Hajiahmadi, S, Esmaeili, S. (2015). Britannin, a sesquiterpene lactone, inhibits proliferation and induces apoptosis through the mitochondrial signaling pathway in human breast cancer cells. Tumor Biology., 36(2):1191-1198. 
Hedinger, C, Dillwyn Williams, E, Sobin, LH. (1989). The WHO histological classification of thyroid tumors: a commentary on the second edition. Cancer, 63(5):908-911.

Hou, P, Liu, D, Shan, Y, Hu, S, Studeman, K, Condouris, S, Wang, Y, Trink, A, El-Naggar, AK, Tallini, G, Vasko, V, Xing, M. (2007).Genetic alterations and their relationship in the phosphatidylinositol 3-kinase/Akt pathway in thyroid cancer.Clin. Cancer Res., 13(4):11611170.

Jafari, E, Gheysarzadeh, A, Mahnam, K, Shahmohammadi, R, Ansari, A, Bakhtyari, H, Mofid, MR. (2018). In silico interaction of insulin-like growth factor binding protein 3 with insulin-like growth factor 1. Res. Pharm. Sci., 13(4):332-342.

Lee, HJ, Lee, WK, Kang, CW, Ku, CR, Cho, YH, Lee, EJ. (2018). A selective cyclin-dependent kinase 4, 6 dual inhibitor, Ribociclib (LEE011) inhibits cell proliferation and induces apoptosis in aggressive thyroid cancer. Cancer Lett., 417:131-140.

Lopes-Ventura, S, Pojo, M, Matias, A, Moura,M, Marques, I, Leite, V, Cavaco, BM. (2018). The efficacy of HRAS and CDK4/6 inhibitors in anaplastic thyroid cancer cell lines.J. Endocrinol. Investigat.,42(5):527-540.

Maleki, F, Noorkhoda, S, Halabian, R, Behzadi, E, Fooladi, AAI. (2018). The Role of Epidermal Growth Factor Receptor in Cancer and their Application for New Targeted Cancer Therapy. J. Clin. Diag. Res., 12(6):XE01-XE06.

Maleki, F, Sadeghifard, N, Hosseini, HM, Bakhtiyari, S, Goleij, Z, Behzadi, E, Sedighian, H, Imani Fooladi, AA. (2019). Growth-inhibitory effects of TGF $\alpha$ L3-SEB chimeric protein on colon cancer cell line.Biomed.Pharmac.,110:190-196.

Markman, B, Tabernero, J, Krop, I, Shapiro, G, Siu, L, Chen, LC, Mita, M, Melendez Cuero, M, Stutvoet, S, Birle, D, Anak, O, Hackl, W, Baselga, J. (2012). Phase I safety, pharmacokinetic, and pharmacodynamic study of the oral phosphatidylinositol-3-kinase and mTOR inhibitor BGT226 in patients with advanced solid tumors. Ann. oncol., 23(9):2399-2408.

Mazzaferri, EL, Kloos, RT. (2001). Current approaches to primary therapy for papillary and follicular thyroid cancer. J. Clin. Endocrinol.Metabolism., 86(4):1447-1463.

Nix, P, Nicolaides, A, Coatesworth, A. (2005). Thyroid cancer review 1: presentation and investigation of thyroid cancer. Int.J. Clin. Pract., 59(11):1340-1344.

Nozhat, Z, Mohammadi-Yeganeh, S, Azizi, F, Zarkesh, M, Hedayati, M. (2018). Effects of metformin on the PI3K/AKT/FOXO1 pathway in anaplastic thyroid Cancer cell lines. DARU J. Pharmac. Sci., 26(2):93-103.

Peyton, J, RodonAhnert, J, Burris, H, Britten, C, Chen, L, Tabernero, J, Duval, V, Rouyrre, N, Silva, AP, Quadt, C, Baselga, J. (2011).A dose-escalation study with the novel formulation of the oral pan-class I PI3K inhibitor BEZ235, solid dispersion system (SDS) sachet, in patients with advanced solid tumors. J.Clin. Oncol., 29(15_suppl):3066-3066. 
Pojo, M, Lopes-Ventura, S, Matias, A, Leite, V, Cavaco, B. (2017). Inhibition of hRAS and CDK4/6 leads to an antiproliferative activity, blocks cell cycle and induces cell death in anaplastic thyroid cancer cell lines. 49, GP126, DOI: 10.1530/endoabs.49.GP126

Pópulo, H, Lopes, JM, Soares, P. (2012). The mTORsignalling pathway in human cancer.Int. J. Molecul. Sci., 13(2):1886-918.

Rahib, L, Smith, BD, Aizenberg, R, Rosenzweig, AB, Fleshman, JM, Matrisian, LM. (2014). Projecting cancer incidence and deaths to 2030: the unexpected burden of thyroid, liver, and pancreas cancers in the United States. Cancer Res., 74(11):2913-2921.

Tagliaferri, L, Gobitti, C, Colloca, GF, Boldrini, L, Farina, E, Furlan, C, Paiar, F, Vianello, F, Basso, M, Cerizza, L, Monari, F, Simontacchi, G, Gambacorta, MA, Lenkowicz, J, Dinapoli, N, Lanzotti, V, Mazzarotto, R, Russi, E, Mangoni, M. (2018). A new standardized data collection system for interdisciplinary thyroid cancer management: Thyroid COBRA. Eur. J. Int. Med., 53:73-78.

Vasko, V, Saji, M, Hardy, E, Kruhlak, M, Larin, A, Savchenko, V, Miyakawa, M, Isozaki, O, Murakami, H, Tsushima, T, Burman, KD, De Micco, C, Ringel, MD. (2004). Akt activation and localisation correlate with tumour invasion and oncogene expression in thyroid cancer. J. Med. Genet., 41(3):161-170.

Vivanco, I, Sawyers, CL. (2002).The phosphatidylinositol 3-kinase-AKT pathway in human cancer.Nat. Rev. Cancer, 2(7):489-501.

Wartofsky, L, Van Nostrand, D. (2016). Thyroid cancer: a comprehensive guide to clinical management: Springer.

$\mathrm{Wu}$, P, Nielsen, TE, Clausen, MH. (2015). FDA-approved small-molecule kinase inhibitors.Trend.Pharmacol. Sci., 36(7):422-439.

Zarkesh, M, Zadeh-Vakili, A, Akbarzadeh, M, Fanaei, SA, Hedayati, M, Azizi, F. (2018).The role of matrix metalloproteinase- 9 as a prognostic biomarker in papillary thyroid cancer. BMC Cancer, 18(1):1199-1210.

How to cite this article:NedaHamidipour, Mehdi Fazeli, Mehdi Hedayati, Mohsen Dehghani, RaziehGerami,PI3K/Akt/mTOR and CDK4 Combined Inhibition Enhanced Apoptosis of Thyroid Cancer Cell Lines.International Journal of Advanced Biological and Biomedical Research, 2020, 8(2), 214-224. Link: http://www.ijabbr.com/article 37195.html 